\title{
PENGARUH KEKASARAN SALURAN DAN SUHU AIR SUNGAI PADA PARAMETER KUALITAS AIR COD, TSS DI SUNGAI WINONGO MENGGUNAKAN SOFTWARE QUAL2KW
}

\author{
Nelly Marlina; Hudori; Ridwan Hafidh \\ Prodi Teknik Lingkungan, Jalan kaliurang km14,5 \\ Email: nelly.marlina@uii.ac.id
}

\begin{abstract}
Abstrak
Penelitian ini bertujuan untuk mengetahui pengaruh dari variabel kekasaran saluran dan suhu air sungai terhadap perubahan kualitas air Sungai Winongo untuk parameter Chemycal Oxygen Demand (COD) dan Total Suspended Solid (TSS). Analisis yang digunakan adalah deskriptif dengan membandingkan hasil konsentrasi skenario pemodelan menggunakan software QUAL2Kw pada tiap variabel dengan variasi kekasaran sebesar 0,016; 0,04; dan 0,15 dan Variasi nilai suhu air sungai $24,2^{\circ} \mathrm{C} ; 28,1^{\circ} \mathrm{C}$; dan $30,6^{\circ} \mathrm{C}$. Hasil pemodelan menunjukkan bahwa pengaruh kekasaran saluran serta kondisi fisik sungai berdampak besar pada konsentrasi polutan pada badan air dengan pendekatan nilai kekasaran pada saluran alami sebesar 0,15 (sig > 0,05). Suhu air sungai akan mengikuti gerak aliran dan buangan polutan yang masuk kedalam badan air dengan menyeimbangkan kondisi fisik sungai yang mengakibatkan turbulensi pada badan air dan berdampak langsung dengan pengaruh yang kecil terhadap COD dan TSS (sig > 0,05), Perubahan kualitas air sungai Winongo dapat diketahui dari grafik dan nilai keluaran dari sofware QUAL2Kw. Dengan strategi pengelolaan mendekatkan kondisi fisik sungai menjadi kondisi alaminya akan menurunkan nilai konsentrasi polutan dan meningkatkan kualitas air sungai menjadi lebih baik.
\end{abstract}

Kata Kunci: COD, Kekasaran Saluran, QUAL2Kw, Strategi Pengelolaan, TSS.

\begin{abstract}
The objective of the study is to determine the effect of roughness variables and temperature to water quality of Winongo River for parameters of Chemycal Oxygen Demand (COD) and Total Suspended Solid (TSS). The analysis that have used is descriptive by comparing the result of modelling scenarios concentration using QUAL2Kw software at every variable with roughness variation at 0,016; 0,04, and 0,15. Result of river water temperature variation at $24,2^{\circ} \mathrm{C} ; 28,1^{\circ} \mathrm{C}$; and $30,6^{\circ} \mathrm{C}$. The modelling result shows that the effect of channel roughness alongside with river physical condition has a big effect on pollutant concentration at water body with closing the value of roughness on natural stream at 0,15 (sig >0,05). The river water temperature will follow the stream movement and discharge of pollutant that enter the water body with balancing the river physical condition that cause a turbulence on water body and has a direct effect with a small cause against COD and TSS (sig > 0,05), The Winongo river water body quality change could be known from a graphic and output value from QUAL2Kw software. With strategy management it may be closed the physical condition into it naturally condition that will be decreasing the value of pollutant concentration and increasing the river water quality into a better quality
\end{abstract}

Keyword: Channel roughness, COD, Management Strategy, QUAL2Kw, TSS.

\section{PENDAhUluan}

Air merupakan bagian atau komponen yang dibutuhkan oleh manusia, sehingga bila dengan kuantitas yang kecil serta pada kualitas yang buruk maka akan menjadi masalah bagi penduduk yang akan menggunakan. Kualitas air Sungai Winongo berbeda dari satu tempat ke tempat lainnya dinilai dari 
parameter fisika, kimia, dan biologinya. Perbedaan nilai tersebut disebabkan oleh dinamika aktifitas warga yang terdapat disepanjang Sungai Winongo. Rendahnya kualitas air sungai ini dapat dilihat dari nilai konsentrasinya yang melebihi baku mutu air kelas II (Pergub no 20 Tahun 2008 tentang Baku Mutu Air di Provinsi DIY) (Yogafanny E, 2015). Disamping itu rendahnya kualitas air ini juga diakibatkan dari beberapa faktor lain, yaitu adanya aktivitas industri seperti industri batik, industri bakpia, industri tahu serta aktifitas peternakan sapi, perikanan dan lain sebagainya.

Penurunan kualitas ini terjadi karena Segala macam limbah dan kotoran dibuang ke sungai tanpa ada pengolahan lebih dahulu. Sungai-sungai yang melewati kota besar pada umumnya kualitas airnya tercemar oleh limbah baik dari industri, rumah tangga, perikanan, dan pertanian. Dampak yang ditimbulkan dari segi kesehatan sangat berbahaya, karena air sungai masih dipergunakan untuk keperluan sehari-hari baik mandi, mencuci ataupun untuk air minum. Polusi air juga akan mengancam habitat ikan di sungai. Sungai yang tercemar dari segi estetika juga tidak nyaman, selain berwarna hitam, banyak sampah yang terapung, juga baunya menyengat (Widodo B, dkk, 2013). Dengan adanya permasalahan tersebut maka penelitian ini dapat membantu untuk menyelesaikan permasalahan dengan memodelkan kualitas air Sungai Winongo serta meningkatkan pemahaman untuk mengetahui pengaruh variable atau komponen yang ada dilingkungan. Adapun penelitian-penelitian terdahulu terkait pengggunaan software Qual2Kw adalah sebagai berikut: Pada tahun 2015 penelitian yang dilakukan oleh Gholipour A, dkk tentang Pengaruh Kekasaran Saluran dan Variasi Suhu dalam Parameter Kualitas Air Limbah Menggunakan Pemodelan Numerik menghasilkan kesimpulan bahwa Pengaruh variasi suhu $30^{\circ} \mathrm{C}$ atau lebih dengan kekasaran saluran (n) lebih dari 0,04 pada seluruh saluran dapat menurunkan nilai konsentrasi pada tiap parameter. Penggambaran saluran berupa penampang yang memiliki keliling basah serta luasan yang dapat menampung serta mengalirkan air dalam jumlah yang besar dan secara massal. Penilaian bentuk pentuk saluran yang dapat diketahui dengan pendekatan perhitungan serta melihat dari karakterisitik fisik saluran alami. Seperti halnya saluran sungai berbatu akan berbeda penilaian dengan sungai berpasir dan berkerikil. Variasi penilaian kekasaran saluran bergantung pada kedalaman sungai dan panjang bentang saluran alami yang dilewati (Gholipour A, dkk, 2015). [e1][L12]Tujuan dari penelitian ini adalah:

1. Menentukan kualitas Sungai Winongo dengan parameter suhu air sungai, $\mathrm{pH}, \mathrm{DO}, \mathrm{TSS}, \mathrm{COD}$

2. Mengetahui pengaruh kekasaran saluran dan suhu air sungai, terhadap kondisi kualitas Sungai Winongo pada parameter COD (Chemical Oxygen Demand[e3]) dan TSS (Total Suspeded Solid[e4]). 
3. Menentukan strategi pengelolaan Sungai Winongo khususnya pada segmen Jlagran, Pendowo, Tamansari, Sugeng Jeroni, Prapanca, Dukuh dan Dongkelan.

\section{METODE PENELITIAN}

\subsection{WILAYAH STUDI}

Sungai Winongo adalah salah satu sungai yang berada di Daerah Istimewa Yogyakarta yang merupakan anak Sungai Opak dengan panjang \pm 41,3 Km, yang mengalir melintasi Kabupaten Sleman, Kota Yogyakarta dan Kabupaten Bantul. Keberadaan Sungai Winongo yang membelah perkotaan Yogyakarta meningkatkan potensi terjadinya pencemaran di Sungai Winongo. Data-data yang digunakan dalam penelitian ini diambil dari data-data hidrolika sungai, data metereologi dan data kualitas serta kuantitas air sungai Winongo. Lokasi-lokasi untuk pengambilan data dalam penelitian ini dapat dilihat pada Tabel 1 .

Tabel 1. Administrasi dan Koordinat Lokasi Pengambilan Sampel

\begin{tabular}{cccccccc}
\hline \multirow{2}{*}{ No. } & Nama & Kelurahan & Kecamatan & Kota/Kabupaten & Kode & Latitude & Longotude \\
$\mathbf{1}$ & $\mathbf{2}$ & $\mathbf{3}$ & $\mathbf{4}$ & $\mathbf{5}$ & $\mathbf{6}$ & $\mathbf{7}$ & $\mathbf{8}$ \\
\hline 1 & Jlagran & Pringgokusuman & Gedong Tengen & Yogyakarta & S.1 & $7^{\circ} 47^{\prime} 23.0^{\prime} \mathrm{S}$ & $1^{\prime} 0^{\circ} 21^{\prime} 23.9^{\prime} \mathrm{E}$ \\
2 & Pendowo & Ngampilan & Ngampilan & Yogyakarta & S.2 & $7^{\circ} 47^{\prime} 53.8^{\prime} \mathrm{S}$ & $110^{\circ} 21^{\prime} 17.4^{\prime} \mathrm{E}$ \\
3 & Tamansari & Notoprajan & Ngampilan & Yogyakarta & S.3 & $7^{\circ} 48^{\prime} 29.0^{\prime} \mathrm{S}$ & $110^{\circ} 21^{\prime} 14.1^{\prime} \mathrm{E}$ \\
4 & Sugeng & Gedong Kiwo & Mantrijeron & Yogyakarta & S.4 & $7^{\circ} 48^{\prime} 44.1^{\prime} \mathrm{S}$ & $110^{\circ} 21^{\prime} 07.8^{\prime} \mathrm{E}$ \\
& Jeroni & & & & & & \\
5 & Prapanca & Gedong Kiwo & Mantrijeron & Yogyakarta & S.5 & $7^{\circ} 49^{\prime} 009^{\prime} \mathrm{S}$ & $1_{110^{\circ} 21^{\prime} 07.6^{\prime} \mathrm{E}}$ \\
6 & Dukuh & Gedong Kiwo & Mantrijeron & Yogyakarta & S.6 & $7^{\circ} 49^{\prime} 27.3^{\prime} \mathrm{S}$ & $1_{110^{\circ} 21^{\prime} 05.6^{\prime} \mathrm{E}}$ \\
7 & Dongkelan & Panggung harjo & Sewon & Bantul & S.7 & $7^{\circ} 49^{\prime} 37.9^{\prime} \mathrm{S}$ & $110^{\circ} 21^{\prime} 06.1^{\prime} \mathrm{E}$ \\
\hline
\end{tabular}

\subsection{PEMBAGIAN SEGMEN SUNGAI}

Tahapan pertama dalam pemodelan dengan menggunakan software[e5] Qual2Kw ini adalah melakukan pembagian segmen sungai. Segmen sungai dibagi sebanyak 6 (enam) segmen. Penelitian ini membutuhkan data primer dan data sekunder. Kegiatan pengumpulan data primer dapat dilakukan dengan observasi lapangan pada sungai. Data primer yang dikumpulkan adalah data debit sungai, data hidrolik, sumber pencemar, dan kualitas air hasil sampling. Kegiatan pengumpulan data sekunder 
meliputi peta administrasi, data klimatologi daerah, data profil sungai, dan data debit serta kualitas limbah industri yang dibuang ke sungai.

\subsection{INPUT DATA QUAL2Kw}

Data hasil pengukuran selanjutnya input ke dalam software QUAL2Kw. Adapun data yang diinput meliputi: lokasi, tanggal, pilihan - pilihan kontrol integrasi numerik, debit dan konsentrasi-konsentrasi parameter di hulu, konsentrasi dan debit untuk point dan diffuse source[e6], panjang ruas, elevasi, geometri hidrolika, temperatur udara, kecepatan angin, tutupan awan, naungan, parameter redaman cahaya, pilihan untuk model radiasi matahari, penguapan (Worksheet 'light and heat'), dan radiasi gelombang panjang, parameter untuk laju dan konstanta kinetika kualitas air (Worksheet 'rates') (Pelletier, 2008).

\subsection{UJI KALIBRASI}

Uji kalibrasi atau uji kemampuan prakiraan model untuk memperoleh nilai variabel - variabel dalam model yang umumnya yang bersifat spesifik lokasi untuk pemodelan transport kontaminan dalam air sungai (Notodarmojo,2005). Kalibrasi adalah proses penentuan harga koefisien yang paling sesuai, sehingga perbandingan hasil model dengan data lapangan menunjukan harga yang paling baik ditinjau secara statistik.

\subsection{UJI VALIDASI}

Menurut Lestari, 2013, Kriteria kuantitatif secara statistik yang digunakan untuk menilai kedekatan model dengan data pengukuran lapangan adalah koefisien validitas model (U). Nilai U berkisar antara 0 hingga 1. Nilai U sama dengan 0 menunjukkan bahwa prediksi model sama dengan data pengukuran lapangan (kesesuaiannya sempurna). Nilai U sama dengan 1 menunjukkan bahwa kesesuaian model dengan lapangan sangat buruk. Nilai U dibawah 0,5 dapat digunakan untuk menyatakan bahwa model dapat diterima (Deksissa, 2004). Berikut ini persamaan yang digunakan untuk menghitung U:

$$
\mathrm{U}=\frac{\sqrt{\frac{1}{n} \sum_{i}^{n}=1(y i, p r d k s-y i, u k r)^{2}}}{\left[\sqrt{\frac{1}{n} \sum_{i}^{n}=1 y i^{2}, p r d k s}+\sqrt{\frac{1}{n} \sum_{i}^{n}=1 y i^{2}, u k r}\right]}
$$

Dimana:

yi, prdks = nilai prediksi pada lokasi $\mathrm{k}$

yi, $\mathrm{ukr} \quad=$ nilai pengukuran pada lokasi ke $\mathrm{i}$

$\mathrm{n} \quad$ = jumlah data pengamatan 


\subsection{SIMULASI / RAKAYASA MODEL}

Model yang telah terkalibrasi dengan baik dimodifikasi untuk melihat pengaruh variabel - variabel dalam menghasilkan output yang diinginkan. Beberapa skenario dalam penelitian ini dilakukan beberapa simulasi diantaranya:

Tabel 2. Skenario Pengembangan Model

\begin{tabular}{|c|c|c|c|c|}
\hline Model & Variabel & Hulu & Sumber Pencemar & Hasil \\
\hline 1 & $\begin{array}{c}\text { Koefisien } \\
\text { Kekasaran Saluran }\end{array}$ & $\begin{array}{l}\text { Kondisi } \\
\text { Eksisting }\end{array}$ & Point Source & $\begin{array}{l}\text { Pengaruh variabel terhadap } \\
\text { konsentrasi parameter. }\end{array}$ \\
\hline 2 & Suhu Air Sungai & $\begin{array}{l}\text { Kondisi } \\
\text { Eksisting }\end{array}$ & Point Source & $\begin{array}{l}\text { Pengaruh variabel terhadap } \\
\text { konsentrasi parameter. }\end{array}$ \\
\hline 3 & $\begin{array}{l}\text { Radiasi Sinar } \\
\text { Matahari }\end{array}$ & $\begin{array}{l}\text { Kondisi } \\
\text { Eksisting }\end{array}$ & Point Source & $\begin{array}{l}\text { Pengaruh variabel terhadap } \\
\text { konsentrasi parameter. }\end{array}$ \\
\hline
\end{tabular}

\section{HASIL DAN PEMBAHASAN}

\subsection{KONDISI KUALITAS AIR SUNGAI WINONGO}

Menurut Mustapa dkk, 2004, Sungai merupakan badan air utama yang digunakan untuk kegiatan domestik, industri, pertanian dan sering membawa limbah perkotaan, air limbah industri dan limpasan musiman dari lahan pertanian. Kualitas air sungai adalah gabungan dari beberapa senyawa yang saling terkait, yang mengalami variasi dari kondisi lokal, temporal dan juga dipengaruhi oleh volume aliran air (Mandal dkk, 2010). Kualitas air dinyatakan dengan parameter yang menggambarkan kondisi air tersebut. Parameter kualitas air meliputi parameter fisika, kimia dan biologi. Parameter tersebut diukur dengan menggunakan metode tertentu sesuai dengan peraturan perundangan yang berlaku. Paramater fisika meliputi suhu, padatan terlarut, padatan tersuspensi. Parameter kimia meliputi pH, TSS, COD, DO. Parameter - parameter tersebut dibandingkan dengan Peraturan Gubernur DIY Nomor 20 Tahun 2008 tentang baku mutu air. Data Hasil pengukuran dan pengamatan kualitas dan kuantitas di lokasi penelitian dari titik 1(satu) sampai dengan titik 7 (tujuh) dilihat pada Tabel 3. 
Tabel 3. Hasil Analisa Kualitas dan Kuantitas Air Sungai Winongo

\begin{tabular}{|c|c|c|c|c|c|c|c|c|c|c|}
\hline \multicolumn{11}{|c|}{ STREAM SOURCE } \\
\hline \multirow{2}{*}{ No. } & \multirow{2}{*}{ Parameter } & \multirow{2}{*}{ Satuan } & \multirow{2}{*}{$\begin{array}{c}\text { Baku } \\
\text { Mutu Air }\end{array}$} & \multicolumn{7}{|c|}{ Hasil Pemantauan } \\
\hline & & & & $\mathrm{S} 1$ & S2 & S3 & S4 & S5 & S6 & S7 \\
\hline 1 & Temperatur & ${ }^{\circ} \mathrm{C}$ & $\pm 3^{\circ} \mathrm{C}$ & 23,5 & 23,9 & 24 & 24,9 & 24,4 & 25,2 & 25,5 \\
\hline 2 & $\mathrm{pH}$ & - & $6,0-8,5$ & 6,3 & 6,8 & 6,6 & 5,9 & 6,5 & 7,6 & 6,4 \\
\hline 3 & Total Suspended Solid (TSS) & $\mathrm{mg} / \mathrm{L}$ & 50 & 87 & 89 & 101 & 105 & 123 & 130 & 128 \\
\hline 4 & Dissolved Oxygen (DO) & $\mathrm{mg} / \mathrm{L} \mathrm{O}_{2}$ & 5 & 4,19 & 4,98 & 3,78 & 4,40 & 4,60 & 5,00 & 5,39 \\
\hline 5 & Cchemycal Oxygen Demand (COD) & $\mathrm{mg} / \mathrm{L}$ & 25 & 26,84 & 27,53 & 25,47 & 50,31 & 17,53 & 10,39 & 9,28 \\
\hline 6 & Debit & $\mathrm{M}^{3} / \mathrm{dt}$ & - & 4,85 & 4,92 & 4,83 & 4,96 & 4,97 & 4,99 & 5,02 \\
\hline
\end{tabular}

Sumber: Data Primer, 2016

Berdasarkan pada Tabel 3, Hasil pengukuran suhu air Sungai Winongo dari titik 1 sampai titik 7 menunjukkan suhu air berkisar antara $23-25{ }^{\circ} \mathrm{C}$. Suhu tertinggi mencapai $25,5{ }^{\circ} \mathrm{C}$ di Desa Panggungharjo Kecamatan Sewon. Suhu air yang tinggi disebabkan oleh intensitas sinar matahari yang masuk ke badan air cukup tinggi karena lokasi pengukuran sampel merupakan daerah terbuka yang terkena sinar matahari secara langsung Intensitas paparan radiasi sinar matahari yang masuk ke badan air serta kerapatan vegetasi di sekitar bantaran sungai juga mempengaruhi suhu air sungai. Semakin banyak intensitas radiasi sinar matahari yang mengenai badan air maka akan membuat suhu air sungai akan semakin tinggi. Vegetasi mempunyai fungsi ekologi antara lain sebagai stabilisator temperature dan kelembaban udara, pemasok oksigen, penyerap $\mathrm{CO}_{2}$ (Sittadewi, E. H,2008).

Padatan tersuspensi air Sungai Winongo dari titik 1 sampai titik 7 menunjukkan TSS berkisar antara 80 - $130 \mathrm{mg} / \mathrm{L}$. Parameter padatan tersuspensi tersebut telah melebihi ambang batas baku mutu air menurut Peraturan Gubernur DIY nomor 20 tahun 2008, dimana baku mutu air kelas II mensyaratkan bahwa padatan tersuspensi dalam air sungai maksimal $50 \mathrm{mg} / \mathrm{L}$. Padatan tersuspensi terdiri dari partikel-partikel yang ukuran maupun beratnya lebih kecil (Stefhany, C.A, dkk, 2013). Pengukuran TSS dilakukan pada bulan februari 2016 dimana pada saat tersebut merupakan musim penghujan. Kondisi air Sungai Winongo pada saat pengambilan sampel cukup keruh karena adanya limpasan air yang berasal dari daratan berupa air dari saluran drainase maupun pipa outlet dari sumber pembuangan limbah. Hal ini sesuai dengan penelitian Ahmad, (2009) bahwa kondisi kualitas air Sungai Bertam, Dataran tinggi Cameron Malaysia menunjukkan telah terjadi peningkatan konsentrasi TSS dalam air sungai pada saat musim hujan dibandingkan pada saat aliran normal (kemarau). Kondisi hujan ini yang menyebabkan nilai TSS di Sungai Winongo melebihi baku mutu yang dipersyaratkan.

Chemical Oxygen Demand (COD) menunjukkan jumlah oksigen yang dibutuhkan untuk mengoksidasi bahan organik secara kimiawi, baik yang dapat didegradasi secara biologis (biodegradable)[e7] maupun yang sukar didegradasi secara biologis (non biodegradable[e8]). Hasil pengukuran parameter COD air 
Sungai Winongo di titik 1 sampai dengan titik 7 menunjukkan nilai COD berkisar antara 9,28 - 27,53 mg/L. Konsentrasi COD dari hulu ke titik 4 cenderung mengalami kenaikan dan mengalami penurunan dari titik 4 menuju hilir. Tingginya konsentrasi COD berkaitan dengan keberadaan bahan organik dalam air yang bersumber dari keberadaan pemukiman penduduk dengan kepadatan yang tinggi (Komarudin, dkk, 2015).

Oksigen terlarut merupakan parameter penting yang digunakan untuk mengetahui kualitas suatu perairan (Salmin, 2005). Hasil pengukuran kadar oksigen terlarut Sungai Winongo di lokasi titik pengambilan sampel 1 sampai dengan titik 7 menunjukkan bahwa nilai oksigen terlarut berkisar antara 3,78 - 5,39 mg/L. Konsentrasi oksigen terlarut tersebut masih memenuhi kriteria mutu air sungai kelas II. Berdasarkan kadar oksigen terlarut dalam air, kondisi kualitas air Sungai Winongo masih dapat digunakan untuk mendukung kehidupan biota air (> $6 \mathrm{mg} / \mathrm{L})$. Sedangkan tingkat pencemaran air Sungai Winongo berada pada tingkat pencemaran rendah merujuk pada pendapat (Salmin ,2005) bahwa suatu perairan yang tingkat pencemarannya rendah dan bisa dikategorikan sebagai perairan yang baik, maka kadar oksigen terlarutnya (DO) > 5 ppm.

\subsection{HASIL SIMULASI SKENARIO DAN ANALISIS DATA OUTPUT MODEL QUAL2Kw}

Disimulasikan dengan membandingkan 3 (tiga) nilai kekasaran saluran (n) yakni nilai rata - rata, minimum, dan maksimum yang diambil dari kondisi fisik sungai yang mengacu pada literatur (Chow, 1959). Dimana nilai kekasaran saluran bersih dan jernih sebesar 0,016; saluran berpasir, kerikil, batu halus dan tanah lempung memiliki nilai kekasaran 0,04; dan saluran dengan cekungan pada bagian sungai, jalur lumpur banjir sebesar 0,15. Nilai dan perubahan konsentrasi pada skenario tersebut dapat dilihat pada Tabel 4. dan Gambar 1.

Tabel 4. Hasil Konsentrasi Skenario Pengaruh kekasaran saluran Terhadap COD

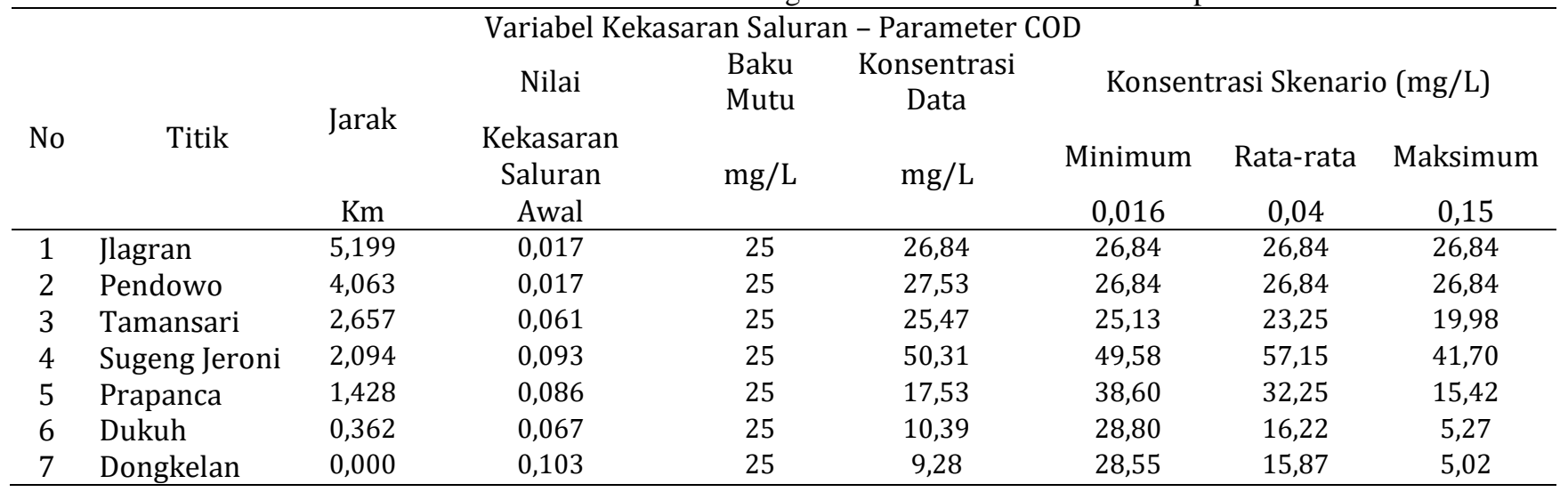




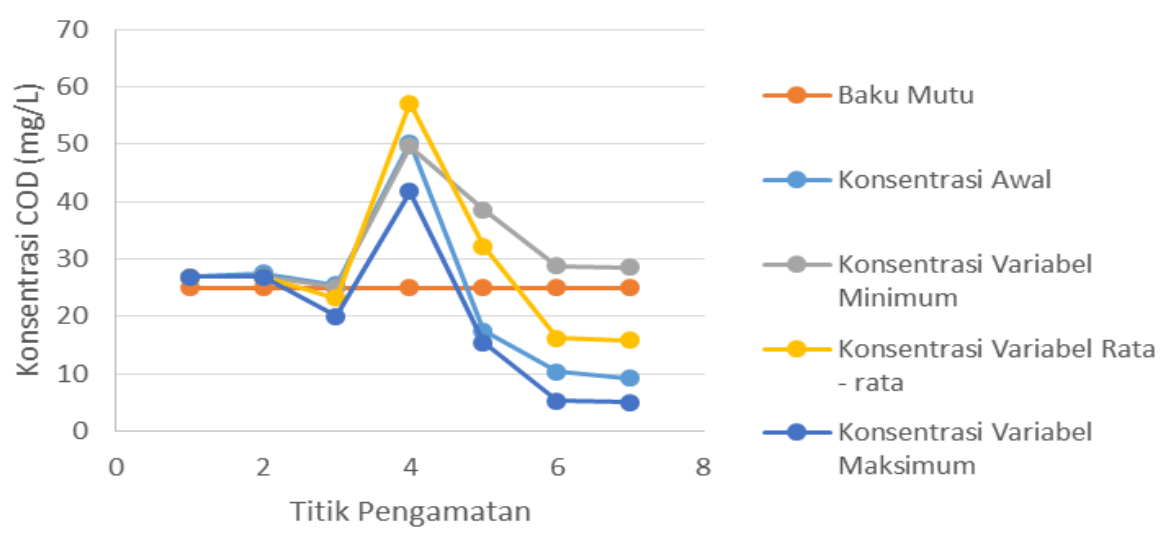

Gambar 1. Grafik Hubungan COD Versus Jarak Untuk Air Sungai Dengan Variasi Nilai Kekasaran Saluran

Pengaruh Hubungan Antara kekasaran saluran dengan parameter COD berdasarkan nilai output software [e9]QUAL2Kw yang diakibatkan oleh meningkatnya kecepatan aliran yang dipengaruhi oleh debit aliran serta kekasaran saluran menunjukkan bahwa semakin besar koefisien manning maka semakin kecil pula konsentrasi COD yang berada dalam badan air. Dapat disimpulkan bahwa keefektifan nilai diupayakan mendekati kondisi maksimum untuk penurunan nilai parameter COD yang signifikan.

Hubungan Antara Suhu Air Sungai dengan parameter TSS yang diakibatkan oleh meningkatnya konsentrasi TSS juga berdampak pada meningkatnya suhu air sungai, oksidasi biologis meningkat bersama meningkatnya suhu perairan sehingga kebutuhan oksigen terlarut juga meningkat (Mahida, 1986), yang menunjukkan bahwa padatan membawa partikel yang menyimpan panas dan mempengaruhi kondisi lingkungan dengan menaikkan suhu air sungai. Disimulasikan dengan membandingkan 3 kondisi yakni rata - rata, minimum, dan maksimum yang diambil dari data sekunder pengukuran BLH D.I.Yogyakarta tahun 2010 - 2015. Dengan nilai suhu minimum $24,2^{\circ} \mathrm{C}$, rerata suhu $28,1{ }^{\circ} \mathrm{C}$, dan Suhu maksimum $30,6^{\circ} \mathrm{C}$ 


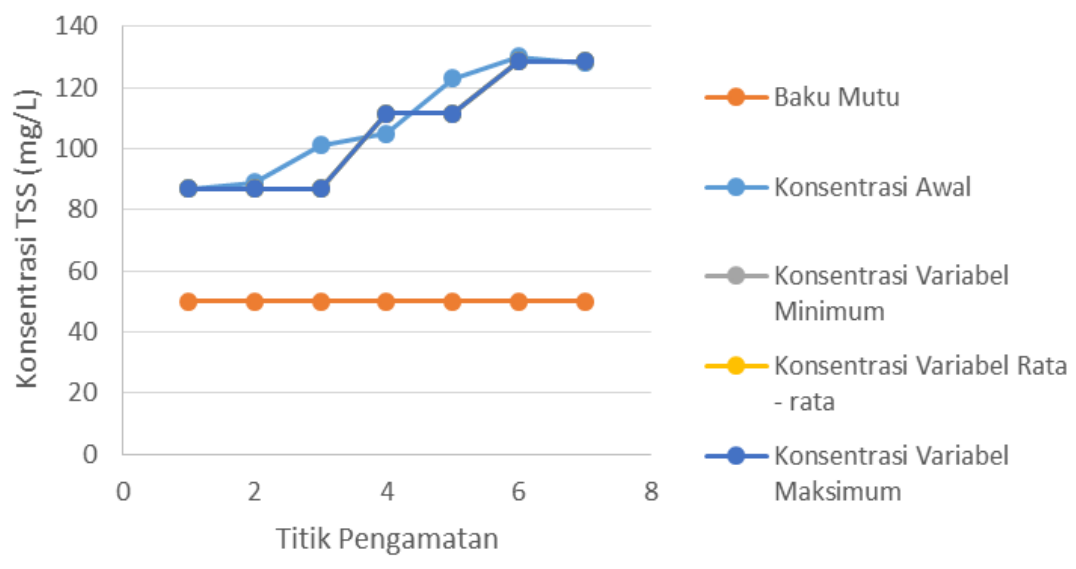

Gambar 2. Grafik Hubungan TSS versus Jarak untuk air sungai dengan variasi nilai suhu air sungai

Dengan nilai suhu minimum $24,2{ }^{\circ} \mathrm{C}$, rerata suhu $28,1{ }^{\circ} \mathrm{C}$, dan Suhu maksimum $30,6{ }^{\circ} \mathrm{C}$, menunjukkan bahwa keefektifan nilai diupayakan mendekati kondisi minimum untuk penurunan nilai parameter TSS karena suhu air sungai pada konsentrasi lapangan sebesar $23,5{ }^{\circ} \mathrm{C}$ dan didapatkan semakin tinggi suhu air sungai semakin bertambah nilai konsentrasi TSS dalam badan air, nilai tersebut tidak berubah pada tiap simulasi, berdasarkan hasil simulasi maka dinyatakan bahwa suhu memiliki pengaruh yang kecil atau tidak ada pengaruh dengan parameter TSS

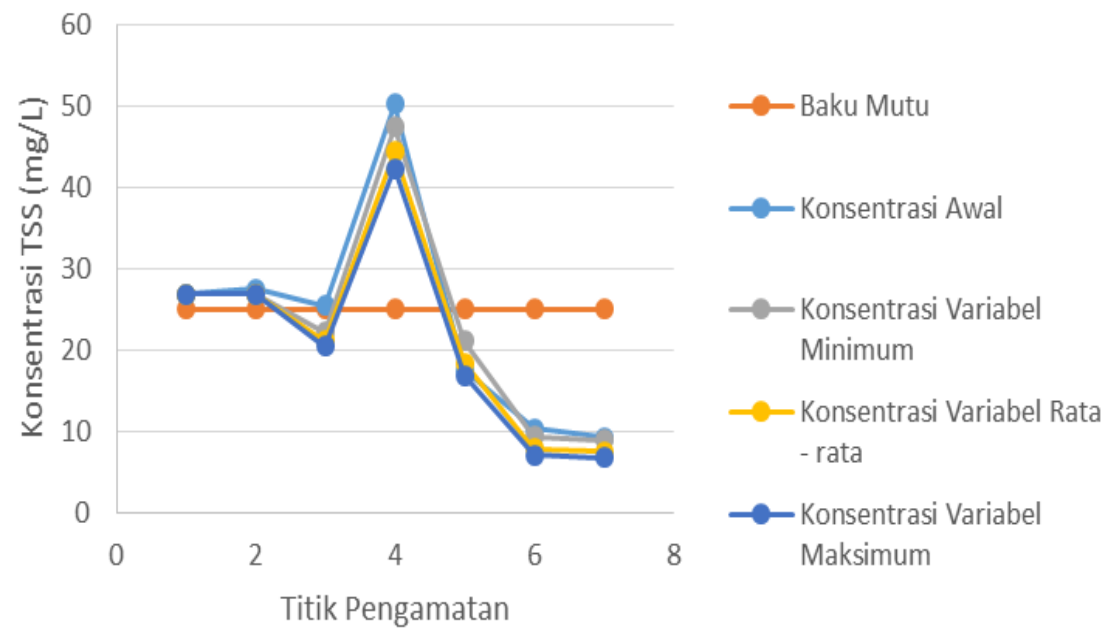

Gambar 3. Grafik Hubungan COD Versus Jarak Untuk Air Sungai Dengan Variasi Nilai Suhu Air Sungai

Berdasarkan Gambar 3, menunjukkan bahwa keefektifan nilai diupayakan mendekati kondisi maksimum untuk penurunan nilai parameter COD karena suhu air sungai pada konsentrasi lapangan sebesar $23,5^{\circ} \mathrm{C}$ dan didapatkan semakin tinggi suhu air sungai semakin berkurang nilai konsentrasi COD dalam badan 
air, nilai tersebut berubah signifikan pada setiap simulasi dan semakin jauh berkurang dari kondisi konsentrasi awal.

\section{KESIMPULAN}

Berdasarkan hasil pemodelan QUAL2Kw yang telah dilakukan terhadap Sungai Winongo dalam penelitian ini, maka dapat disimpulkan bahwa:

1. Kualitas air sungai Winongo mengalami fluktuasi dari titik pertama hingga titik terakhir. Parameter yang telah melebihi baku mutu air kelas II adalah COD dan TSS

2. Peningkatan nilai kekasaran saluran (n) meningkatkan laju alir atau kecepatan aliran pada badan sungai yang mengakibatkan turbulensi dan mengontakkan oksigen dengan badan air sehingga dapat menurunkan nilai COD dan TSS.

3. Pada penelitian sebelumnya dan mengacu pada teori bahwa penurunan suhu air sungai akan meningkatkan nilai konsentrasi DO tidak ditunjukkan pada kondisi Sungai Winongo, Kerena dengan memodelkan menaikkan suhu air sungai dapat mempercepat degradasi dan dekomposisi bahan organik maupun non organik serna dapat meningkatkan laju alir / kecepatan aliran akibat tumbukan antar partakel yang diseimbangkan dengan kondisi fisik sungai guna mencapai aliran yang turbulen sehingga dapat menurunkan nilai COD dan TSS dan menaikkannilai konsentrasi DO.

4. Strategi pengelolaan untuk menjaga kualitas air Sungai Winongo. Dapat disarankan upaya pengelolaan oleh pihak seperti pemerhati Sungai Winongo, Badan Lingkungan Hidup, dan Pemerintah, yakni:

a. Mengembalikan kondisi sungai secara alami

b. Penanaman pohon secara intensif pada bantaran sungai akan mampu mendukung kondisi fisik sungai untuk memulihkan atau menurunkan nilai COD dan TSS pada kondisi yang lebih baik (dibawah baku mutu).

c. Mengusahakan agar air lebih banyak meresap ke dalam tanah di hulu dan di bagian tengah DAS Winongo segmen tengah dapat dilakukan dengan menanam pohon dan/atau dengan tindakan konservasi sipil teknis seperti pembuatan sumur resapan, biopori dan sebagainya pada bantaran sungai guna menahan laju limpasan dari air sungai maupun air limbah.

d. Tingginya sedimentasi di sungai dikendalikan dengan meningkatan fungsi filter dapat ditempuh dengan penanaman rumput, belukar, dan pohon pohonan atau dengan membuat bangunan jebakan sedimen pada bantaran sungai. 


\section{UCAPAN TERIMA KASIH}

Terimakasih kepada semua pihak yang telah membantu atas terlaksananya penelitian ini terutama kepada Program Studi Teknik Lingkungan Universitas Islam Indonesia

\section{DAFTAR PUSTAKA}

Ahmad, R.Z, (2009). Cemaran Kapang pada Pakan dan Pengendaliannya. Balai Besar Veteriner, Jurnal Litbang Pertanian. Vol 28 (1). Hal. 15-22.

Badan Lingkungan Hidup, (2014). Laporan Status Lingkungan Hidup Daerah (SLHD) Daerah Istimewa Yogyakarta. Yogyakarta: Badan Lingkungan Hidup Provinsi DIY

Deksissa, T, (2004). Dynamic integrated modelling of basic water quality and fate and effect of organik contaminants in rivers, Ph.D Thesis. Belgium: Ghent University.

Gholipour A, Alamatian E, Foerstener N, (2015). Assessing of Channel Roughness and Temperature Variation on Wastewater Quality Patamaters Using Numerical Modeling. Mashhad: Master Science of Wastewater Engineering, Khavaran Institute of Higher Education, Mashhad, Iran.

Komarudin M, Hariyadi S, Kurniawan B, (2015). Analisis Daya Tampung Beban Pencemar Sungai Pesanggrahan (Segmen Kota Depok) Dengan Menggunakan Model Numerik Dan Spasial. Jurnal Pengelolaan Sumberdaya Alam dan Lingkungan. Vol. 5 No. 2. Hal. 121-132.

Lestari A D N, (2013). Penerapan Model Qual2Kw Dalam Mempelajari Pengaruh Lebar sungai Terhadap Proses Swapurifikasi Beban Pencemar Bahan Organik (Studi Kasus: Sungai GajahWong, Yogyakarta. ISTECH Vol 5 No 2. Hal. 109-114.

Mustapha, A., A. Z. Aris, H. Juahir, M. F. Ramli, N. Kura, (2013). River water quality Assessment using envirometric technique: case study of Jakarta River Basin. Environ Sci Pollut Res. Doi:10.1007/s11356-013-1542-z.

Mandal, P., Upadhyay, R., Hasa, A, (2010). Seasonal and spatial variation of Yamuna River water quality in Delhi, India. Environ Monit Assess 170 (1):661-670. doi:10.1007/s10661-009-1265-2.

Mahida, U.N, (1986). Pencemaran dan Pemanfaatan Limbah Industri. Rajawali Press, Jakarta Notodarmojo, S (2005). Pencemaran Tanah dan Air Tanah. Bandung: ITB 
Pelletier, Z.G dan Chapra. S.C, (2008). QUAL2K: A Modeling Framework for Simulating River and Stream Water Quality (Version 2.11): Documentation and User Manual. Medford, MA: Civil and Environmental Engineerimg Dept., Tufts University.

Salmin, (2005). Oksigen Terlarut (DO) dan Kebutuhan Oksigen Biologi (BOD) Sebagai Salah Satu Indikator Untuk Menentukan Kualitas Perairan. Oseana Volume XXX No. 3, Hal. 1-6.

Sittadewi, E.H (2008). Identifikasi Vegetasi Di Koridor Sungai Siak dan Peranannya dalam Penerapan Metode Bioengineering. Jurnal Sains dan Teknologi Indonesia Vol 10. Hal. 112-118.

Stefhany, C.A, Sutisna M dan Pharmawati K. (2013). Fitoremediasi Phospat dengan menggunakan Tumbuhan Enceng Gondok pada Limbah Cair Industri Kecil Pencucian Pakaian. Jurnal Institut Teknologi Nasional. Vol.1. Hal. 1-11.

Chow, V.T, (1959). Open Channel Hydraulics. New York: McGraw-Hill Book Co.

Widodo B., Kasam, Ribut L, dan Ike A, (2013).Strategi Penurunan Pencemaran Limbah Domestik di Sungai Code DIY. Jurnal Sains dan Teknologi Lingkungan Vol 5, No 1 Hal. 36-47.

Yogafanny E, (2015), Pengaruh Aktifitas Warga di Sempadan Sungai terhadap Kualitas Air Sungai Winongo. Jurnal Sains dan Teknologi Lingkungan Vol 7, No 1 Hal. 41-50. 